\title{
Malarial Hepatopathy in Children Visiting a Tertiary Healthcare Hospital in Karachi
}

\author{
Nathumal Maheshwari ${ }^{1}$, Mehmood Shaikh ${ }^{2,3}$, Rewa Chand ${ }^{4}$, Hemandas Maheshwari ${ }^{5}$, Mehrunnisa Yasir
} 6

1. Pediatrics, Shaheed Mohtarma Benazir Bhutto Medical College, Karachi, PAK 2. Neonatal Intensive Care Unit, Jinnah Sindh Medical University, Karachi, PAK 3. Neonatology, National Institute of Child Health, Karachi, PAK 4. Pediatric Surgery, Shaheed Mohtarma Benazir Bhutto Medical College, Karachi, PAK 5. Pediatrics, St. Richard's Hospital, Chichester, GBR 6. Medical Intensive Care Unit, National Institute of Child Health, Karachi, PAK

Corresponding author: Mehrunnisa Yasir, dr.mehrunnisa.syed@gmail.com

\section{Abstract}

\section{Objective}

To determine the frequency of malarial hepatopathy in children that are visiting Lyari General Hospital in Karachi, Pakistan.

\section{Study design}

Cross sectional descriptive study.

\section{Material and methods}

Patients with age between two months and 15 years, who had positive blood film for Plasmodium falciparum or P. vivax, were included in the study. All patients were monitored for malarial hepatopathy.

\section{Result}

A total of 241 cases were included in the study. Mean age at admission was $4.1 \pm 1.3$ years and male to female ratio was 1.2:1. There were 133 (55.2\%) cases of P. vivax, while 108 (44.8\%) were of P. falciparum. Malarial hepatopathy was observed in 37 patients (15.4\%). Malaria hepatopathy was present in $24.1 \%$ and $8.3 \%$ children having P. falciparum and P. vivax, respectively. Malaria hepatopathy was present in $24 \%, 18 \%$ and $6 \%$ in age groups two months to five years, $>5$ years to 10 years and $>10$ years, respectively.

\section{Conclusion}

Malarial hepatopathy was observed in about one-sixth of study population and it was more common between two months and five years age group.

Received 01/01/2020

Review began 01/08/2020 Review ended 01/13/2020 Published 01/18/2020

() Copyright 2020

Maheshwari et al. This is an open access article distributed under the terms of the Creative Commons Attribution License CC-BY 3.0., which permits unrestricted use, distribution, and reproduction in any medium, provided the original author and source are credited.
Categories: Pediatrics, Gastroenterology, Infectious Disease

Keywords: plasmodium falciparum, plasmodium vivax, malarial hepatopathy

\section{Introduction}

Malaria is one of the leading causes of morbidity and mortality in children worldwide [1]. Malaria is generally caused by four Plasmodium species (falciparum, malariae, vivax and ovale). In the islands of Borneo and peninsular Malaysia malaria occurred due to fifth species, Plasmodium knowlesi but the most dangerous species are P. falciparum and P. vivax $[2,3]$.

Malaria is the second most frequently observed disease in under-developed countries [4]. It is endemic in more than one hundred countries, predominately in Africa, Asia, Central America, and South America with about $40 \%$ of the world's population at risk [5-8]. P. falciparum and P. vivax are endemic in Pakistan [9]. Agricultural practice, irrigation network, and monsoon rains are major factors to enhance the malarial potential in many areas [4].

According to the World Health Organization (WHO), in 2015 there were an estimated 429,000 deaths worldwide due to malaria, of which $99 \%$ were due to P. falciparum alone. Seventy percent (approximately $303,000)$ of the global estimate were of children under the age of five years [10].

Malaria in children can mimic many diseases and there are no absolute clinical features [11]. It may present with high grade fever with chills, headache, sweating, myalgia, abdominal pain, vomiting, diarrhea, anemia, hepatomegaly, splenomegaly and jaundice [12]. In endemic regions, malaria can present atypically due to development of immunity, increasing resistance to antimalarial drugs, and the indiscriminate use of 
antimalarial drugs [1]. The most common complications of malaria are disseminated intravascular coagulation (DIC), hepatopathy, cerebral malaria, acute kidney injury, hypoglycemia and severe anemia [13, 14]. Hepatic dysfunction is common in either isolated P. falciparum or a mixed infection with P. vivax [15]. Jaundice in malaria is due to intravascular hemolysis of parasitized erythrocytes, hepatic dysfunction and DIC [16]. Severe jaundice is reported from many countries of South-east Asia, but according to the WHO the signs of gross hepatocyte dysfunction and hepatic encephalopathy do not occur in these patients [11]. Malaria hepatitis is described by hyperbilirubinemia (> $3 \mathrm{mg} / \mathrm{dl})$, elevated transaminase more than three folds the normal levels and in the absence of clinical or serological evidence of viral hepatitis [17].

There is a paucity of data related to malarial hepatopathy worldwide. Hence, we decided to conduct this study at our tertiary care center.

\section{Materials And Methods}

This was a cross sectional descriptive study conducted at Pediatrics Department, Shaheed Mohtarma Benazir Bhutto Medical College, Lyari Karachi and Lyari General Hospital, Karachi for a period of six months from May to October 2018. The study was initiated after approval from the Institutional Review Board and obtaining informed consent from the parents/guardian. Patients with age between two months to 15 years, who had positive blood film for Plasmodium falciparum or P. vivax, were included in the study by consecutive non-probability sampling, until the desired number of patients was completed. Criteria used to diagnose malarial hepatopathy were demonstration of Plasmodium infection: falciparum/vivax, with serum bilirubin $>3 \mathrm{mg} / \mathrm{dl}$ and at least two to three-fold rise in transaminases enzymes (alanine transaminase, aspartate aminotransferase) and normal or abnormal prothrombin time (PT). Patients with evidence of liver disease or enteric hepatitis were excluded from the study. Data including history and examination were collected on specially designed proforma. Investigations included complete blood counts, peripheral blood film for detailed morphology of RBCs, thick and thin blood films for malarial parasites, prothrombin time, total serum bilirubin, conjugated and unconjugated bilirubin, and serum aspartate transaminase (AST) and alanine transaminase (ALT) levels. Results were analyzed using SPSS version 20 (IBM Corp., Armonk, NY). Qualitative variable was presented as frequency and percentages, while quantitative variables presented in mean and standard deviation.

\section{Results}

A total of 241 cases of blood smear positive for Plasmodium falciparum/vivax were included in the study. Out of 241 patients, 130 were males (53.9\%) and 111 were females (46.1\%) resulting in male:female ratio of 1.2:1. Mean age at admission was $4.1 \pm 1.3$ years (ranged from $0.5-13$ years). There were 133 (55.2\%) cases of P. vivax, while 108 (44.8\%) of P. falciparum. Mean serum bilirubin level, serum alanine transferase (ALT) and aspartate amino transferase (AST) were $1.8 \pm 4.5 \mathrm{mg} / \mathrm{dl} \pm \mathrm{SD}$ (Range: $0.2-26 \mathrm{mg} / \mathrm{dl}$ ), $40.1 \pm 46.2 \mathrm{IU} / \mathrm{L} \pm \mathrm{SD}$ (Range: $9-165 \mathrm{IU} / \mathrm{L}$ ) and $35.6 \pm 41.3 \mathrm{IU} / \mathrm{L} \pm \mathrm{SD}$ (Range: $10-189 \mathrm{IU} / \mathrm{L}$ ), respectively. Abnormal PT was seen only in $27(11.2 \%)$ children. Majority $(140 ; 58 \%)$ of children were aged between two months and five years (Figure $1)$.

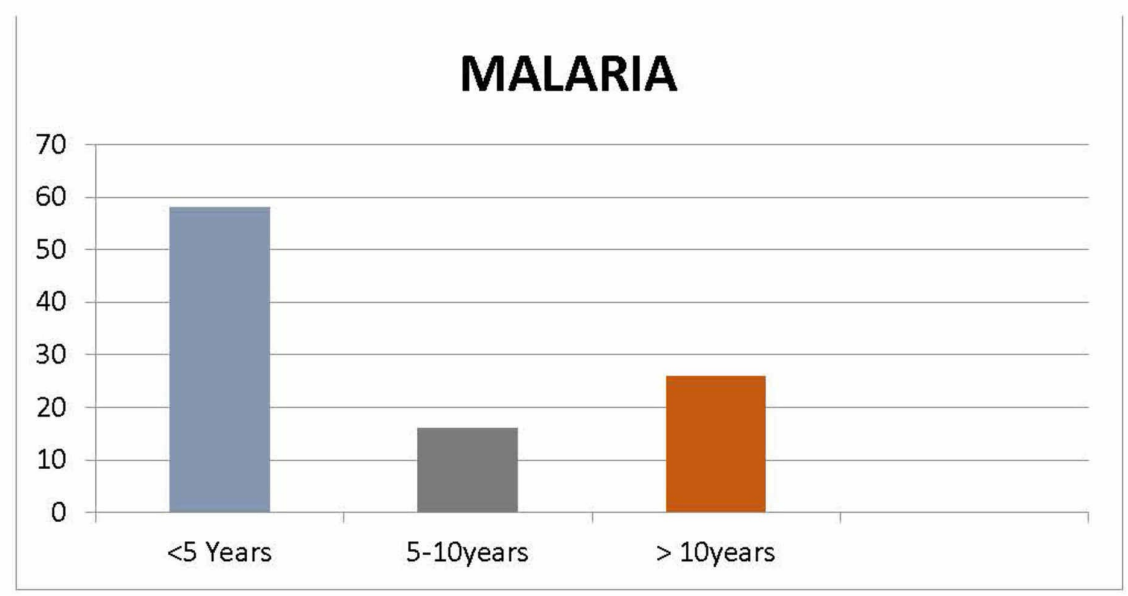

FIGURE 1: Age of the patients with malaria.

In 37 patients (15.4\%), serum transaminase level was more than thrice the upper limit of normal levels. There were 22 males (59.4\%) and 15 females (40.6\%), with male:female of 1.46:1. Mean age of children with malarial hepatopathy was $3.1 \pm 1.1$ years with a range of $0.5-12.5$ years. Majority $(9 ; 24.2 \%)$ of children had age between two months and five years (Figure 2). 


\section{Cureus}

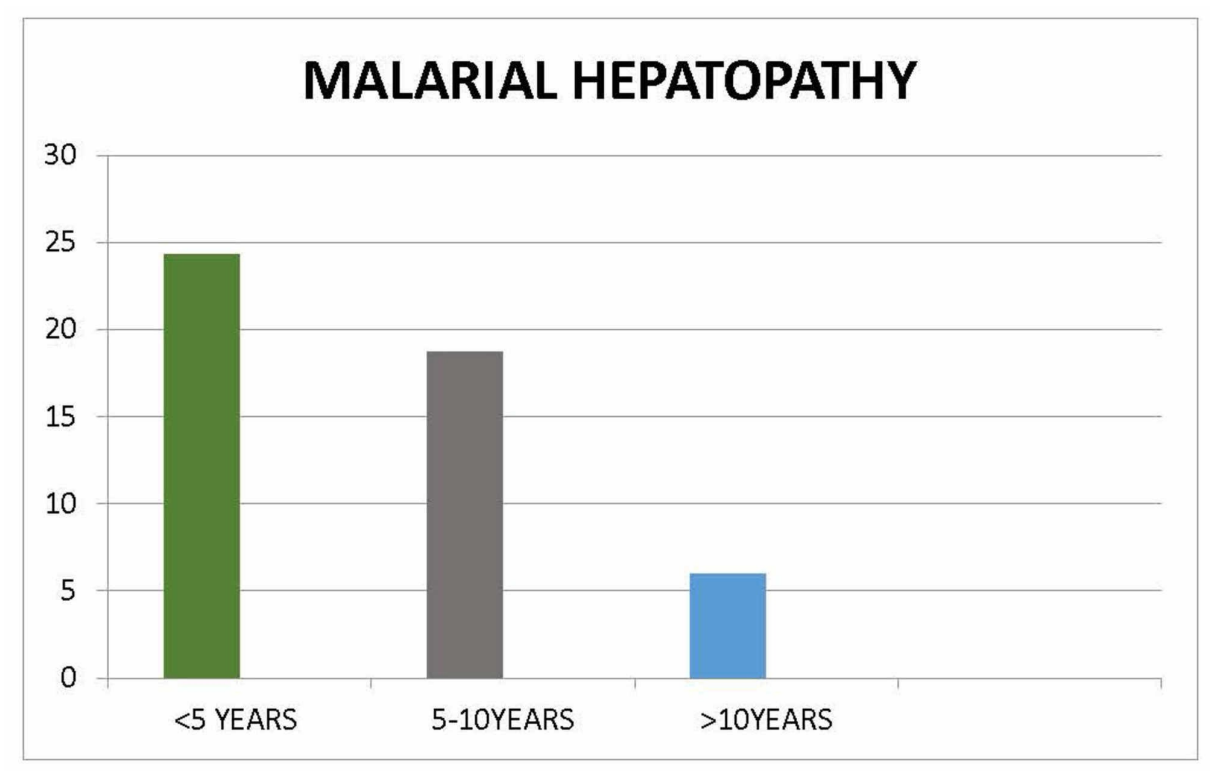

FIGURE 2: Age of the patients with malaria hepatopathy.

Mean serum bilirubin level, serum ALT and AST in malarial hepatopathy patients were $13.1 \pm 9.3 \mathrm{mg} / \mathrm{dl} \pm \mathrm{SD}$ (Range: $12-26 \mathrm{mg} / \mathrm{dl}$ ), $125.2 \pm 8.2 \mathrm{IU} / \mathrm{L} \pm$ SD (Range: $120-165 \mathrm{IU} / \mathrm{L}$ ) and $116.2 \pm 6.3 \mathrm{IU} / \mathrm{L} \pm$ SD (Range: $110-189$ $\mathrm{IU} / \mathrm{L})$, respectively. Malarial hepatopathy with respect to the type of Plasmodium is shown in Table 1.

\begin{tabular}{|l|l|l|l|}
\hline Type & Total & Malarial Hepatopathy & Percent \\
\hline Plasmodium vivax & 133 & 11 & 8.3 \\
\hline Plasmodium falciparum & 108 & 26 & 24.1 \\
\hline
\end{tabular}

TABLE 1: Malarial hepatopathy with respect to type of plasmodium.

\section{Discussion}

Malaria remains a serious health problem worldwide, which threatens millions of people and inflicts a huge burden in terms of complications and mortality [18-22]. Jaundice is one of the severe manifestations of malaria. It may present alone or with other complication of malaria and vary in intensity. The spectrum of presentation ranges from mild jaundice due to the hemolysis to severe jaundice due to hepatic dysfunction [23].

Out of 241 patients, 130 were males (53.9\%) and 111 were females (46.1\%) resulting in male:female ratio of $1.2: 1$, which is consistent with Hussain et al., Kochar et al. and Sahar et al. [4,24,25]. Male predominance may be due to more outdoor activities as compared to female.

In our study, frequency of P. vivax was more common than P. falciparum which is consistent with other studies done by Hussain et al. and Nadeem et al. [4, 26]. However, it was contrary to another study by Khadim and Akbar [27, 28].

Hepatic dysfunction in children was found to be $15.35 \%$ which was contrary to other study by Mannu et al. [29]. P. falciparum showed hepatopathy in $32.2 \%$ of cases in Indian study done by Satpathy et al. [30]. The results are conformity with our study where hepatopathy due to P. falciparum was in $24.1 \%$ cases. In comparison to study by Kochar et al., which showed that hepatic hepatopathy was present in $44.3 \%$ (35/79), $26.2 \%(17 / 65)$ and $16.7 \%(1 / 6)$ children having P. falciparum, P. vivax and mixed infections, respectively [24]. Our study revealed malaria hepatopathy was present in $24.1 \%$ and $8.3 \%$ children having P. falciparum and P. vivax, respectively. In a study conducted by Kochar et al., it was described that hepatic hepatopathy was present in $24.7 \%, 17.9 \%$ and $6.6 \%$ in the age groups of two months to five years, $>5$ years to 10 years and $>10$ years, respectively [24]. The results are in conformity with our study. 


\section{Conclusions}

Malarial hepatopathy was observed in about one-sixth of study population and interestingly it was found to be more common in children between two months and five years. We, therefore, conclude that screening for hepatopathy should be mandatory in patients that have P. falciparum and P. vivax infections. Further studies with large sample sizes are required to fully understand malarial hepatopathy in depth.

\section{Additional Information \\ Disclosures}

Human subjects: Consent was obtained by all participants in this study. IRB of Shaheed Mohtarma Benazir Bhutto Medical College, Lyari issued approval F-SMBBMCL/(ERC)/2018-19/039. Ethical approval has been taken from the IRB of Shaheed Mohtarma Benazir Bhutto Medical College, Lyari. Animal subjects: All authors have confirmed that this study did not involve animal subjects or tissue. Conflicts of interest: In compliance with the ICMJE uniform disclosure form, all authors declare the following: Payment/services info: All authors have declared that no financial support was received from any organization for the submitted work. Financial relationships: All authors have declared that they have no financial relationships at present or within the previous three years with any organizations that might have an interest in the submitted work. Intellectual property info: This study was previously submitted in the Infectious Diseases Journal of Pakistan but was withdrawn by us for publication in Cureus. Other relationships: All authors have declared that there are no other relationships or activities that could appear to have influenced the submitted work.

\section{References}

1. Zaki SA, Shanbag P: Atypical manifestations of malaria. Res Rep Trop Med. 2011, 2:9-22. 10.2147/RRTM.S13431

2. Elsheikha HM, Sheashaa HA: Epidemiology, pathophysiology, management and outcome of renal dysfunction associated with plasmodia infection. Parasitol Res. 2007, 101:1183. 10.1007/s00436-007-0650-4

3. Cox-Singh J, Davis TM, Lee K-S, et al.: Plasmodium knowlesi malaria in humans is widely distributed and potentially life threatening. Clin Infect Dis. 2008, 46:165-171. 10.1086/524888

4. Hussain K, Shafee M, Khan N, Jan S, Tareen A, Khan M: Seroprevalence of pediatric malaria in Quetta, Balochistan, Pakistan. Iran J Parasitol. 2013, 8:342-347.

5. Portugal S, Moebius J, Skinner J, et al.: Exposure-dependent control of malaria-induced inflammation in children. PLoS Pathog. 2014, 10:e1004079. 10.1371/journal.ppat.1004079

6. Jamal MM, Ara J, Ali N: Malaria in pediatric age group: a study of 200 cases . Pak Armed Forces Med J. 2005, 55:74-77.

7. Worku B, Haileamlak A: Pattern and trend of severe and complicated malaria among children, Jimma University Specialized Hospital, Southwest Ethiopia. Ethiop J Health Sci. 2009, 19:139-146.

8. Asma U-e, Taufiq F, Khan W: Prevalence and clinical manifestations of malaria in Aligarh, India . Korean J Parasitol. 2014, 52:621-629. 10.3347/kjp.2014.52.6.621

9. Shaikh S, Memon H, Iohano B, Shaikh A, Ahmed I, Baird JK: Severe disease in children hospitalized with a diagnosis of Plasmodium vivax in south-eastern Pakistan. Malaria J. 2012, 11:144. 10.1186/1475-2875-11144

10. Fact sheet: World Malaria Report 2016. (2016). Accessed: December 28, 2019: https://www.who.int/malaria/media/world-malaria-report-2016/en/.

11. Shah S, Ali L, Sattar RA, Aziz T, Ansari T, Ara J: Malarial hepatopathy in falciparum malaria . J Coll Physicians Surg Pak. 2009, 19:367-370.

12. Krause P, Behrman R, Kliegman R, Jenson H: Malaria (Plasmodium) - Nelson Textbook of Pediatrics. Elsevier, 2007.

13. Ahmed S, Adil F, Shahzad T, Yahiya Y: Severe malaria in children: factors predictive of outcome and response to Quinine. J Pak Med Assoc. 2011, 61:54.

14. Cook G, Zumla A: Manson’s Tropical Diseases. Saunders, London; 2009.

15. Fazil A, Vernekar PV, Geriani D, et al.: Clinical profile and complication of malaria hepatopathy. J Infect Public Health. 2013, 6:383-388. 10.1016/j.jiph.2013.04.003

16. Singh R, Kaur M, Arora D: A prospective study of hepatic involvement in Plasmodium falciparum malaria . J Clin Diagnostic Res. 2010, 4:2190-2197.

17. Saya RP, Debabrata G, Saya GK: Malarial hepatopathy and its outcome in India . North Am J Med Sci. 2012, 4:449-452. 10.4103/1947-2714.101981

18. Menezes RG, Kanchan T, Rai S, et al.: An autopsy case of sudden unexplained death caused by malaria . J Forensic Sci. 2010, 55:835-838. 10.1111/j.1556-4029.2010.01328.x

19. Menezes RG, Pant S, Kharoshah MA, et al.: Autopsy discoveries of death from malaria . Legal Med. 2012, 14:111-115. 10.1016/j.legalmed.2012.01.007

20. Pradhan SK, Mutalik P, Subudhi T, Swain A, Mohanty N: Outcomes of paediatric malarial hepatopathy: a study from Eastern India. Paediatr Indones. 2014, 54:256-259. 10.14238/pi54.5.2014.256-9

21. Nizamani A, Kalar N, Khushk I: Burden of malaria in Sindh, Pakistan: a two years surveillance report . J LUMHS. 2006, 5:76-83.

22. Dongmo FD, Ngane RN, Gouado I, et al.: Predictors of childhood severe malaria in a densely populated area: Douala, Cameroon. Afr J Biotechnol. 2011, 10:6319-6324.

23. Sianti E, Mandei JM: Confusions and dilemma around hepatic dysfunction associated falciparum malaria: a case report and brief review of the literature. Paediatr Indones. 2009, 49:244-248. 10.14238/pi49.4.2009.244-8 


\section{Cureus}

24. Kochar DK, Tanwar GS, Khatri PC, et al.: Clinical features of children hospitalized with malaria-a study from Bikaner, northwest India. Am J Trop Med Hyg. 2010, 83:981-989. 10.4269/ajtmh.2010.09-0633

25. Sahar S, Akhtar T, Bilal H, Rana M: Prevalence of Plasmodium falciparum, malarial parasite in Muzaffargarh district, Punjab, Pakistan: a two year study. Pak J Sci. 2012, 64:64-66.

26. Nadeem M, Ali N, Qamar MA: Hematological findings in acute malarial infection list of authors along with highest qualification and institute. Biomedica. 2002, 18:62-65.

27. Khadim MT: Malaria: a menace at Zhob Garrison. Pak Armed Forces Med J. 2002, 52:203-207.

28. Akbar JU: Malaria in children at a children hospital . J Surg Pak Int. 2002, 7:20-22.

29. Mannu A, Agarwalla SK, Vasudevan J, Subramaniam K, Ahamed Basha A: Hepatic dysfunction in children with complicated malaria. Int J Contemp Pediatrics. 2018, 5:5-28. 10.18203/2349-3291.ijcp20180552

30. Satpathy S, Mohanty N, Nanda P, Samal G: Severe falciparum malaria. Indian J Pediatr. 2004, 71:133-135. 10.1007/BF02723094 